$\widehat{\mathcal{S}}_{\text {https://doi.org/10.3765/sp.12.6 }}^{\text {Semantics \& Pragmatics Volume 12, Article 6: 1-36, } 2019}$

\title{
The proprial article and the semantics of names*
}

\author{
Patrick Muñoz \\ University of Chicago
}

Submitted 2018-06-30 / First decision 2018-08-27 / Revision received 2018-09-30 / Second decision 2018-10-10 / Revision received 2018-10-12 / Accepted 2018-10-13 / Published 2019-11-14 / Final typesetting 2023-03-02

\begin{abstract}
The proprial article is a functional item that occurs in a number of languages alongside names to the general exclusion of other nouns. In the following I present an account of the semantic function of this article, and how it interacts with names as nouns to form referential expressions in argument position. In particular, I suggest that in line with what a number of researchers have claimed, names generally are count nouns in the lexicon, denoting the property of bearing the name in question. The proprial article then composes with name NPs of a certain sort to yield proprial DPS that rigidly denote individuals, which are presupposed to bear the name in question at their world of use. It follows that ordinary referential names in argument position are not definite descriptions, as related approaches to the semantics of names often suppose, and that the proprial article is a functional element distinct from the definite article. This schema is applied to DP languages with article systems generally: all such languages are taken to have the proprial article, whether it appears overtly or covertly, and to make use of proprial DPs for reference using names. The machinery used further allows for a model-theoretically precise and intuitively compelling characterization of name-bearing.
\end{abstract}

Keywords: names, name-bearing, proprial article, reference, definite descriptions, variables

* Thanks to: Chris Kennedy, Aidan Gray, Malte Willer, and Itamar Francez, for discussion of the material that led to this paper; the audiences of the 2oth Amsterdam Colloquium and the Semantics Babble group at UC San Diego, to which I presented earlier stages of this research; and the reviewers of this paper at Semantics \& Pragmatics, for their rigor, patience, and invaluable suggestions during revision.

(C)2019 Patrick Munoz

This is an open-access article distributed under the terms of a Creative Commons Attribution License (https://creativecommons.org/licenses/by/3.o/). 
Patrick Muñoz

\section{Introduction: the proprial article}

A number of languages have an article of a special form that occurs adjacent to names, called the proprial article. The proprial article is found, among many other languages, in Tagalog (Campbell 1991: p. 1587), Māori (Harlow 2001: pp. 28-29), Catalan (Coromina i Pou 2001), Icelandic (Sigurðsson 2006; Wood 2009), and certain dialects of Norwegian and Swedish (Delsing 1993: pp. 54-55).

For instance, the proprial article in Māori is $a$. It occurs to the immediate left of names, which in ordinary referential uses are ungrammatical absent the article, in subject position (1a) or as the object of certain prepositions, including in direct object position (1b)-(1c); in other contexts, referential uses of names occur bare, with no overt article (Bauer 2003: pp. 142-144). ${ }^{1}$
a. Ka whakarongo puku a Ponga. TAM listen silent PROP Ponga
'Ponga listened in silence.'
[Māori. Bauer 2003: p. 143]
b. ... ka pōwhiri i a Ponga.
TAM wave DO PROP Ponga
'.... [she] beckoned Ponga.'
[ibid.]
c. ... ka kake katoa mai ngā tāngata ki runga i a
TAM climb-on all hither the.PL people to top at PROP Mātaatua ...
Mataatua
'... all the people climbed onto Mataatua...'
[ibid.]

The proprial article in Māori has a form distinct from definite articles, including the singular determiner te and the plural determiner $n g \bar{a}$. These combine with non-name NPs in the usual way. Note the occurrence of both proprial and definite articles in (2a).

(2) a. ... kātahi rā anō a Puhihuia ka whakaaro, te kotiro o then dist again PROP Puhihuia TAM decide the girl of te rangatira ...

the chief

'...then Puhihuia, the daughter of the chief...decided...'

[ibid. pp. 144-145]

1 In what follows I always gloss the proprial article as 'PROP' for terminological consistency. All other glosses and translations are from the cited source material. $\mathrm{Ka}$, glossed 'TAM,' is a tense marker; $i$, glossed 'DO,' is a preposition heading a direct object PP. 
The proprial article and the semantics of names

b. ...mā.u e unga i $\bar{o}$ hoa kia haere ki ō-mātou belong.2.SG TAM send DO your friend TAM move to our waka i Onehunga, kia kotikoti-a ngā here-here o ngā canoe at Onehunga TAM cut.PASs the.PL tie.DUP of the.PL rauawa.

side

'...you should tell your friends to go to our canoes at Onehunga, to cut the lashings of the sides.'

[ibid. p. 146]

The proprial article is highly selective with its complements, occurring grammatically with names to the exclusion of other nouns (with some exceptions: see Section 4.3). This suggests that the proprial article is a unique functional element, whose limited distribution reflects a function important to the semantics of names specifically.

In what follows I offer a semantics for the proprial article, and a semantics for names as nouns, that accounts for their composition in forming referential names in argument position. I suggest that the proprial article is theoretically crucial for providing a cross-linguistic semantics of names, and that recognizing its existence as a unique functional element, and in particular an element distinct from the definite article, resolves several extant problems in the literature surrounding said semantics. In brief, I propose that ordinary referential names in argument position are proprial DPs in DP languages with article systems, which are the result of composition between the proprial article and the right sort of NP containing a name noun. Proprial DPs denote individuals, but in a manner distinct from definite descriptions.

Section 2 outlines a prominent extant treatment of names, to be adopted here, according to which names are count nouns in the lexicon that denote the property of bearing the name in question. I survey the attractiveness of this position, along with its extant problems. I then then suggest that the proprial article is key to resolving these problems, and acts as a functional element that converts name-headed NPs into rigidly referring DPs occurring in argument position. Section 3 contains the account that makes good on this suggestion, and provides a semantics for names, the proprial article, and their composition, along with a model-theoretically precise and intuitively plausible characterization of name-bearing. Section 4 offers some comments on the proposal, and Section 5 concludes. 
Patrick Muñoz

\section{Names as name-bearing count nouns}

A prominent treatment of names takes them to be count nouns in the lexicon that denote the property of bearing the name in question. For instance, a lexical entry for John is as follows.

(3) $\llbracket$ John $\rrbracket^{w}=\lambda x_{e} \cdot x$ bears John at $w$

John is therefore an ordinary nominal predicate, true of all Johns at the world of evaluation, or true of all individuals named John. ${ }^{2}$

This view is appealing, since names occur in a huge variety of nominal predicative positions, rather than in argument position, with exactly this interpretation. First, they appear with a variety of quantificational determiners and nominal morphology to form arguments. ${ }^{3}$

(4) a. Every John that I've met is smart.

b. I know three Samanthas.

c. Which Mary went to the party?

d. Kyles are annoying.

The truth conditions of these sentences transparently reflect the proposal: for example, (4a) is true just in case every individual named John that the speaker has met is smart, such that John is roughly paraphrasable as individual named John.

Second, names occur as vocatives, like ordinary nominal predicates, and unlike ordinary referential arguments. ${ }^{4}$

2 This position can be found in Sloat 1969 and Burge 1973, and has enjoyed a more recent revival in Matushansky 2008, Gray 2012, and Fara 2015b, among others. Closely related views are found in Kneale 1962, Loar 1976, Bach 1981, and Geurts 1997.

3 The extent to which names can occur with these markers is subject to cross-linguistic variation. Schoubye (2017: p. 738) notes that in several North Germanic languages, predicative names have impoverished inflectional morphology, and can't occur with plural marking: $\mathrm{cf}$. Leckie 2013: p. 1158 for a similar observation about French names. This is unsurprising: as Fara (2015b: pp. 77-78) notes, there's no reason to expect names to be identical in their behavior to non-name count nouns. In fact, we know independently that they are not, but form a unique morphosyntactic class; cf. Matushansky 2006: pp. 297-298 for a small list of cross-linguistic idiosyncrasies affecting names to the exclusion of other nouns.

4 A reviewer notes that this datum is complicated by the fact that certain arguments can function as vocatives, including you and everyone, so that John may be occurring as an argument in (5a), not as a nominal predicate. But there is independent evidence that this isn't so: in languages like modern Greek (Holton et al. 2012: p. 357), where an article is obligatory for names in argument position, name-vocatives must occur without the article, and so they occur as nouns (cf. Delsing 1993: pp. 54-55 for a similar observation about northern Swedish 
The proprial article and the semantics of names

(5) a. John, I'd like a glass of beer.

b. $\quad$ Waiter / Kid / Barkeep\}, I'd like a glass of beer.

c. *The manager, I'd like a glass of beer.

The felicity conditions of (5a) transparently reflect the proposal: it is felicitous only if addressed to an individual named John, just as (5b) is felicitous only if addressed to a waiter, kid, or barkeep.

Third, as Matushansky (2008) has shown, names occur in predicative position beneath small clause-embedding verbs like call and name (e.g., in My parents named me John), and in many languages they appear there with predicate marking, or case-marking characteristic of predicates. In such constructions, names also occur without articles, even in languages in which such articles are obligatory in argument position, marking them as non-arguments (ibid. Sections 2.4-2.6). ${ }^{5}$

The position that names are nouns that denote name-bearing properties thus has a great deal of explanatory power. An alternate position, for example on which names are simply individual-denoting expressions in the lexicon, whether as nouns or arguments, must come up with some alternate explanation for all of these phenomena (cf. Section 4.3). Yet the position outlined here has a number of extant problems noted in the literature: Section 2.1 reviews them, and Section 2.2 suggests that the proprial article offers a solution to them.

\subsection{Problems with referential names as descriptions}

The question remains, given the above treatment of names as count nouns, of how to account for the occurrence of names as referential expressions

vocatives, and Perini 2002: p. 333 for the same with Portuguese vocatives). One can still claim that the name-vocative occurs as a noun, but not as a predicate; but this is to suggest that nominal vocatives have a split semantics, and requires an independent explanation of the semantics of names in vocative position specifically.

5 The semantics of such constructions is a tougher issue than with the previous examples, as can be seen from Matushansky 2008. But a plausible interpretation for example of My parents named me John is that it is true just in case the parents of the speaker performed an onomastic act that resulted in the speaker coming to have the property that John denotes, that is the property of being named John. This fits naturally with the present treatment of names. By contrast, a semantics for this sentence on which John refers to some individual named John is hopeless. Matushansky in ibid. also argues from the case-marking of predicative names in languages like Russian against a quotative analysis of such constructions: they are not to be read with John denoting the name John, rather than its ordinary denotation. 
in argument position. The going hypothesis (entertained in Elbourne 2005, Matushansky 2008, Gray 2012, and Fara 2015b, a.o.) is that in such positions, name NPs compose with the definite article to form an argument. This is meant to be transparently reflected in languages like modern Greek and many varieties of (especially spoken) Portuguese, where an article that shares its form with the definite article is often obligatory for such names in argument position. ${ }^{6}$

(6) O Días eínai planetes. 'Jupiter is a planet.'

[Greek. Holton et al. 2012: p. 356]

(7) O Manuel te ligou ontem. 'Manuel called you yesterday.' [Portuguese. Perini 2002: p. 333]

Some explanation is then required for why in a number of languages with a definite article, names in argument position occur bare, with no overt article. Here some morphosyntactic constraint is postulated, which obligatorily contracts the definite article into the name, or has it occur phonologically null, in the required environments. Matushansky (2006: pp. 296-303) and Fara (2015b: p. 93) offer explicit formulations of such a constraint. Thus for example in English, (8a) is in some sense a surface realization of what would otherwise be (8b).

(8) a. John went to the store.

b. The John went to the store.

The suggestion that referential names in argument position always occur with the definite article has difficulties with the cross-linguistic distribution of articles and names in argument position.

First, as noted in Section 2.1, many languages have a proprial article whose overt form differs from the definite article in the same language. In such cases, ordinary referential names in argument position do not occur with the definite article, but rather with the proprial article. Matushansky (2006: pp. 303-304) addresses this by positing that the proprial article is a special phonological realization of the definite article, triggered via a local morphophonological operation, the same that causes the definite article to appear null in bare-name languages. This is problematic, since proprial and definite articles can have distinct distributional properties even in the same

6 In Greek, $o$ is the singular masculine nominative definite article; in Portuguese, $o$ is also the masculine singular definite article. 
The proprial article and the semantics of names

language: for example, Sigurðsson (2006: p. 226) notes that in Icelandic, ordinary referential names, when they occur with an article, must take the proprial article to their left, while the definite article can occur either to the left of nouns, or suffixed to their right, including with names (as in (16c) below).

Second, in bare-name languages, such a proposal predicts that the bare name (e.g., John) occurs as argument, but the DP containing just the definite article and the name (e.g., the John), does not, since the latter construction triggers contraction of the article. Since Sloat 1969, it has often been assumed that expressions like the John do not occur in bare-name languages, making this seem like a welcome result, but Jeshion (2015) has shown at length that this isn't so, and that for example John and the John both occur in English, in contrastive distribution. They also have distinct interpretations, as will be shown shortly.

But the more substantive problems with the proposal are semantic. If referential names in argument position are the result of a name composing with the definite article, it follows that said names are definite descriptions. Given a standard Strawsonian treatment of the definite article (9a), it follows that for example in English, John, occurring in argument position with the contracted article, refers to the unique individual, within some restricted domain, named John at the world of evaluation (9c).

(9) a. $\llbracket$ the $\rrbracket^{w}=\lambda P_{\langle e, t\rangle} . \iota x[P(x)]$

b. $\llbracket J o h n \rrbracket^{w}=\lambda x_{e} \cdot x$ bears John at $w$

c. $\llbracket \varnothing_{\text {the }} \mathrm{John} \rrbracket^{w}=\iota x[x$ bears John at $w]$

But bare names in general do not behave semantically like definite descriptions of this sort. First, referential names and definite descriptions with name NPs don't equally license bound readings of domain restrictions.

(10) a. In every race, John wins.

b. In every race, the John wins.

The most salient reading of (10a) is that in every race, some one individual (say, $j$ ) wins; the most salient reading of (1ob) is one on which in every race,

7 It remains an interesting puzzle why expressions like the John are pragmatically impoverished, and only felicitous in restricted contexts, so that researchers for a long time thought them ungrammatical. While I don't have an answer for this, my sympathies lie with a pragmatic account orthogonal to the present concerns, since similar simple descriptions that have far more conventional counterparts to be used in acts of reference, like the person (as compared to $s /$ he: cf. the John versus John), seem to be similarly impoverished. 
the individual named John in that race (possibly different Johns in different races) wins. It is more difficult to read (10a) with the covariation between races and Johns. ${ }^{8}$

Second, referential names are typically rigid beneath world- and timeintensional operators, whereas definite descriptions with name NPs are not, and participate easily in de dicto readings, where their extensions vary with the point of evaluation.

a. Smith always cheats.

b. The Smith always cheats.

(12) a. Smith might cheat.

b. The Smith might cheat.

(13) a. If we hadn't hired a proctor, Smith would have cheated.

b. If we hadn't hired a proctor, the Smith would have cheated.

Where some teachers are talking about the administration of an exam, all of the above (b)-sentences easily allow readings where the one named Smith taking the relevant exam (whoever it might be, possibly distinct Smiths in distinct circumstances) is the potential cheater (say, if people named Smith are notorious for this as a group). ${ }^{9}$ The (a)-sentences, by contrast, more stringently enforce rigid readings, wherein some single individual actually named Smith, invariant across points of evaluation, is the potential cheater.

Thus while the thesis that names are predicates denoting name-bearing properties is appealing, the thesis that referential names are in general definite descriptions is not. ${ }^{10}$ If names are taken to be name-bearing count nouns, it would be worthwhile to consider alternate mechanisms for generating referential names in argument position from name NPs.

8 Hawthorne \& Manley (2012: pp. 236-237) discuss these sorts of cases. Fara (2015a) claims that the descriptive view can handle them; see Schoubye 2016 for a rebuttal. A reading of (10a) on which the Johns covary with the races is apparently possible for some speakers, but the contrast is clear.

9 Note that Smith here is not to be read as denoting membership of a single family Smith: the covariation is possible even if what unites the Smiths is their name alone.

10 There are a number of further minor problems with the definite description thesis. Gray (2018) notes that definite descriptions, but not referential names, license one-anaphora with their nominal material, and Hawthorne \& Manley (2012: p. 235) note that the former, but not the latter, can have their nominal material act as antecedent to also. 
The proprial article and the semantics of names

\subsection{Referential names as proprial DPs}

Researchers wanting to treat names as name-bearing count nouns have been sensitive to the problems accompanying the view that referential names in argument position are always definite descriptions, especially with respect to the apparent rigidity of such names, and so have sought a mechanism to convert names into rigid arguments. The most common approach is to alter or clarify the semantics of definite descriptions with names in some way that yields the desired results: this is attempted for example in Elbourne 2005, Matushansky 2008, and Fara 2015b, all of which are critically examined in Schoubye 2018, where it is argued that the approaches on offer are either non-explanatory or empirically inadequate.

Gray (2018) has more radically entertained the idea that the mechanism that converts name-bearing nouns into referential arguments ought not to be identified with the definite article at all. Instead, the conversion might take place via a lexical rule, or via a distinct idiosyncratic determiner occurring with names (Gray 2017). The latter is the direction to be explored here: the overt appearance of such a determiner distinct from the definite article motivates such a position clearly.

The proprial article, I suggest, is what everyone has been looking for, and performs the desired function. It is a functional element distinct from the definite article, and its semantic role is to take a name-bearing predicate into a rigidly referential expression. Thus for example in Māori, a selects for an NP to yield a DP consisting of the name and the article, as on the following highly simplified representation of the referential name a Ponga; I refer to such DPs occurring in argument position as proprial DPs or proprial names.

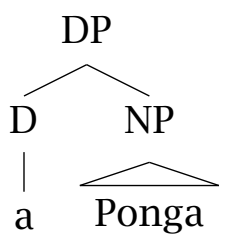

The proprial article appears in many forms cross-linguistically: there are languages like Māori in which it has a distinct form, while in other languages, it shares a form with some other functional item, as in Icelandic, where it is homophonous with certain personal pronouns (cf. Sigurðsson 2006: Section 4). But having said this, there is no reason not to think that the proprial article can't also sometimes occur as homophonous with the definite article, or 
bare: these are simply alternate typological realizations of its morphophonological form. I therefore propose that in languages like modern Greek and Portuguese, the article occurring with referential names as in (6) and (7) is the proprial article as well - it just happens to look like the definite article in a restricted class of languages.

As to bare proprial articles, it is already independently commonplace to treat referential names in bare-name languages like English as containing a phonologically null D-element (e.g., in Longobardi 1994: pp. 628-632). I claim that languages like English, therefore, have the proprial article as well, but it just happens to be silent. In saying this, I propose to identify the silent D in such languages with its overt counterpart in languages like Māori.

There is some cross-linguistic evidence for this assimilation. With names, the null article (or overt absence of an article) in bare-name languages patterns closely with the appearance of the overt proprial article in languages that contain it, across a variety of constructions, besides the obvious analogy that they both occur with referential names generally in argument position.

For instance, in bare-name languages, names can't occur without an overt article when modified by a restrictive relative clause: here, the definite article must appear, and the name must be read predicatively, such that (15b)'s intended interpretation is, 'the individual named Mary that I know is a lawyer.'

(15) a. *Mary that I know is a lawyer.

b. The Mary that I know is a lawyer.

In languages with an overt proprial article that has a form distinct from the definite article, the analogous is true: names cannot occur with restrictive relative clauses with the proprial article, but must appear with the definite article, and be read predicatively. ${ }^{11}$
a. Ko te Hone e kōrero nei, kāhore e roa. TOP the John TAM talk nearI NEG TAM tall 'The John I'm talking about isn't tall.' [Māori. Bauer 2003: p. 159]
b. el Pau que vam conèixer a la festa the Paul that go.1.PL meet at the party 'the Paul that we met at the party'

[Catalan. Matushansky 2008: p. 608]

11 The singular, masculine proprial article in Catalan is en; the singular, masculine definite article is $e l$. In Icelandic, the singular feminine nominative proprial article is hún, while the postnominal definite article is the suffix $-n$. 
The proprial article and the semantics of names

c. Dú ert fyrsta María-n sem ég kynnist. you are first.DEF Maria-the who I get-to-know 'You are the first Maria I get [sic] to know.'

[Icelandic. Sigurðsson 2006: p. 226]

Further evidence for assimilation comes from quasi-names (cf. Pelczar \& Rainsbury 1998: pp. 298-301), which are items that behave syntactically and semantically like argument-position names, but take the form of (usually relational) nouns typically not thought to be names, like mom (as in, Mom went to the airport). Which nouns can occur also as quasi-names exhibits cross-linguistic regularities, and these very same nouns, when occurring as quasi-names, occur without an overt article in English, and with a proprial article in Icelandic (Sigurðsson 2006: pp. 224-225). Pairs include dad / pabbi, grandma / amma, and marginally, teacher / kennari.

Thus, I take (14) to be a schema for referential names in argument position, in DP languages that have article systems generally. In said languages, ordinary referential names in argument position are proprial DPs consisting of both a proprial article and a name noun, and that article varies in its overt or covert form. This is why such names most often do not look like definite descriptions, and why they generally do not behave like them. They are not definite descriptions; they are proprial DPs. The following will provide an account of their semantic behavior.

\section{The account}

This section provides the promised account that resolves the issues discussed in Section 2.1. Section 3.1 introduces some basic model-theoretic machinery, and defines an intuitively plausible notion of name-bearing in terms of it. Section 3.2 then imports this notion of name-bearing to characterize the semantics of names as nouns denoting name-bearing properties, in line with the position outlined in Section 2. Section 3.3 describes the semantics of the proprial article, and how it composes with name NPs to return rigidly designating DPs. Finally, Section 3.4 demonstrates how the pragmatics behaves with respect to the machinery of referential indices introduced in Section 3.1, and how it follows from all the previously-defined machinery that proprial name DPs presuppose that their referents bear the name in question at their world of use. 
Patrick Muñoz

\subsection{Name-bearing}

First, we define a notion of name-bearing that respects the following intuitive principle: for an individual to bear a name (at a world) is just for that individual to be a conventionally possible referent of that name (as used at that world). This is done using a characterization of referential indices, of the sort typically used to treat variable expressions, which requires some preliminary setup in the model theory and compositional semantics. Section 3.4 will make explicit how this machinery ties into acts of reference using names.

We define a set of types recursively, and assign them corresponding domains, as follows.

(17) a. $e, t$ are types;

b. If $\sigma$ is a type, then $\langle\langle v, e\rangle,\langle s, \sigma\rangle\rangle$ is a type;

c. If $\sigma, \tau$ are types, then $\langle\sigma, \tau\rangle$ is a type;

d. Nothing else is a type.

$$
\begin{aligned}
& \text { a. } \mathscr{D}_{e}=\{x: x \text { is an individual }\} \\
& \text { b. } \mathscr{D}_{t}=\{\text { true, false }\} \\
& \text { c. } \mathscr{D}_{s}=\{w: w \text { is a possible world }\} \\
& \text { d. } \mathscr{D}_{v}=\{1,2,3 \ldots\} \\
& \text { e. } \mathscr{D}_{\langle\sigma, \tau\rangle}=\left\{f: f \text { is a partial function } \mathscr{D}_{\sigma} \rightarrow \mathscr{D}_{\tau}\right\}^{12}
\end{aligned}
$$

$\mathscr{D}_{v}$ is the domain of referential indices, here represented by the set of nonzero natural numbers (18d). An assignment function (assignment) is a partial function from referential indices to individuals, that is an object in the domain $\mathscr{D}_{\langle v, e\rangle}$. The clause (17b) defines intensional types, whose domains are functions from assignments to possible worlds to extensional types.

Let $(\cdot)$ be an interpretation function, that is a partial function from expressions $\alpha$ to intensions $\in \mathscr{D}_{\langle\langle v, e\rangle,\langle s, \sigma\rangle\rangle}$, where $\sigma$ is some type. Let $\llbracket \alpha \rrbracket^{g, w}$ then be the extension of $\alpha$ at assignment $g$ and world $w$, namely $(\alpha)(g)(w)$, so that each extension is resolved relative to these two intensional parameters. Where $\llbracket \alpha \rrbracket^{g, w} \in \mathscr{D}_{\sigma}$, we say that $\alpha$ is of type $\sigma$.

Expressions are then at-most binary-branching labeled trees, including lone leaves, and $\ell \cdot D$ is constrained by (extensional and intensional) function application.

12 Here and throughout, 'partial function' trivially includes total functions. 
The proprial article and the semantics of names

(19) If the set of daughters of $\alpha$ is $\{\beta, \gamma\}$, then $\llbracket \alpha \rrbracket^{g, w}=$

a. $\quad \llbracket \beta \rrbracket^{g, w}\left(\llbracket \gamma \rrbracket^{g, w}\right)$ or $\llbracket \gamma \rrbracket^{g, w}\left(\llbracket \beta \rrbracket^{g, w}\right)$, or

b. $\llbracket \beta \rrbracket^{g, w}((\gamma))$ or $\llbracket \gamma \rrbracket^{g, w}((\beta))$, whichever (if any) is defined.

Next, we isolate certain referential indices, to be associated with particular names in the language. For any name $n$, let $\mathscr{V}_{n} \subset \mathscr{D}_{v}$ be the denumerably infinite set of indices associated with $n$ : thus in English, $\mathscr{V}_{\text {John }}$ is the set of indices associated with the name John, and so on. Let any $\mathscr{V}_{n}, \mathscr{V}_{n^{\prime}}$, where $n \neq n^{\prime}$, be disjoint; it's otherwise immaterial which numbers are included in each set. Further, let there be a denumerably infinite set of indices $\mathscr{V}_{\varnothing}$, associated with no name - these are the indices that take part in non-namerelated reference, for example using pronouns.

Now let $\mathscr{G}(w)$ be the set of assignments $g \in \mathscr{D}_{\langle v, e\rangle}$ in force at world $w .^{13}$ For $g$ to be in force at $w$ is for it to be one of the referential mappings conventionally available to the speech community at $w$ : it is one of the associations between indices and individuals that linguistic convention licenses (what this means pragmatically will be clarified in Section 3.4). Typically, $\mathscr{G}(w)$ is a proper subset of $\mathscr{D}_{\langle v, e\rangle}$, such that at $w$ some assignments are licensed, and others are not.

We next define a notion of name-bearing at a world, in terms of whether the indices associated with a certain name map to a certain individual on assignments licensed at that world. More explicitly, where $g[i \rightarrow x]$ is that assignment just like $g$ except that $g[i \rightarrow x](i)=x$ :

(20) $\quad x$ bears $n$ at $w$ iff:

For all $g \in \mathscr{G}(w), i \in \mathscr{V}_{n}: g[i \rightarrow x] \in \mathscr{G}(w)$.

In prose: an individual bears a name at a world where minimally altering any assignment licensed at that world, to map any index associated with that name to that individual, still yields a licensed assignment. At $w$, the indices associated with $n$ are thus conventionally permitted to map to $x$, wherever this mapping doesn't interfere with other restrictions on licensed assignments.

This in turn allows for a characterization of what happens when individuals come to bear names: this involves a minimal extension of the licensed assignments to accommodate the definition in (20). Let DUB be a function from triples of sets of assignments, individuals, and names $\langle G, x, n\rangle$ to sets

13 The allusion here is to Pelczar \& Rainsbury's (1998) notion of dubbings in force. 
of assignments $G^{\prime}$, where $G^{\prime}$ is the set of assignments resulting from altering $G$ minimally such that according to $G^{\prime}, x$ bears $n$. We define DUB recursively:

$\operatorname{DUB}(G, x, n)$ is the smallest set such that:

a. If $g \in G$, then $g \in \operatorname{DUB}(G, x, n)$;

b. If $g \in \operatorname{DUB}(G, x, n)$, then for all $i \in \mathscr{V}_{n}: g[i \rightarrow x] \in \operatorname{DUB}(G, x, n)$.

It follows from the definitions in (20) and (21) that for any set of assignments $\mathscr{G}(w)$ that is the result of applying DUB to some triple $\langle G, x, n\rangle, x$ bears $n$ at $w$, as desired. ${ }^{14}$ If at $w, x$ acquires the name $n$, then the world-state alters to some $w^{\prime}$, such that $\mathscr{G}\left(w^{\prime}\right)=\operatorname{DUB}(\mathscr{G}(w), x, n) .^{15}$

Finally, we restrict the space of possible sets of licensed assignments by ensuring that all sets of licensed assignments are well-behaved. This simply means that whenever some assignment licensed at a world maps some index associated with a certain name to a certain individual, then that individual bears that name at that world, according to the definition in (20).

a. $\mathscr{G}(w)$ is well-behaved iff:

For all individuals $x$, names $n$ :

if there is some $i \in \mathscr{V}_{n}, g \in \mathscr{G}(w)$ such that $g(i)=x$, then $x$ bears $n$ at $w$ (per the definition in (20)).

b. For all $w: \mathscr{G}(w)$ is well-behaved.

Thus name-bearing consists in having restricted referential indices map to individuals according to the assignments licensed at a world. This notion can then be imported to characterize the semantics of names.

\subsection{Names}

As in Section 2, we treat names as count nouns in the lexicon, which denote the property of bearing the name in question. This can be implemented by importing the definition of name-bearing given in (20) in Section 2.1 above.

14 Proof: Let $\mathscr{G}(w)=\operatorname{DUB}(G, x, n)$. Then for arbitrary $g \in \mathscr{G}(w), i^{\prime} \in \mathscr{V}_{n}$ : by (21b), instantiating $i$ ' for $i$, and replacing 'DUB $(G, x, n)$ ' with the equivalent ' $\mathscr{G}(w)$,' we have: 'If $g \in \mathscr{G}(w)$, then $g\left[i^{\prime} \rightarrow x\right] \in \mathscr{G}(w)$.' Therefore by modus ponens, $g\left[i^{\prime} \rightarrow x\right] \in \mathscr{G}(w)$. Since this was done for arbitrary $g \in \mathscr{G}(w), i^{\prime} \in \mathscr{V}_{n}$, the universal in (20) is fulfilled, and it follows that $x$ bears $n$ at $w$, Q.E.D.

15 This definition need not be used only for acts of dubbing, but can describe the force of any of the infinite ways in which an individual comes to bear a name. An analogous notion of an individual losing a name can also be defined, in terms of assignments going out of force. 
The proprial article and the semantics of names

Thus the schema for the denotation of a name $n$ is as in (23a), and the schema instantiated for John is as in (23b).

$$
\begin{array}{r}
\text { a. } \llbracket n \rrbracket^{g, w}=\lambda x_{e} \cdot \forall g^{\prime} \in \mathscr{G}(w), i \in \mathscr{V}_{n}\left[g^{\prime}[i \rightarrow x] \in \mathscr{G}(w)\right] \\
=\lambda x_{e} \cdot x \text { bears } n \text { at } w \\
\text { b. } \llbracket J \mathrm{John} \rrbracket^{g, w}=\lambda x_{e} . \forall g^{\prime} \in \mathscr{G}(w), i \in \mathscr{V}_{J o h n}\left[g^{\prime}[i \rightarrow x] \in \mathscr{G}(w)\right] \\
=\lambda x_{e} \cdot x \text { bears John at } w
\end{array}
$$

Thus John is true of $x$ at $w$ just in case $x$ is a John at $w$, that is just in case the assignments in force at $w$ conventionally allow the mapping of John-indices to $x$.

All sorts of predicative uses of names as in (4) are given the desired interpretation by this lexical entry, and names as ordinary count nouns can occur in principle with the distribution of ordinary NPs, as desired. Note also that the extensions in (23) are world-sensitive, and hence name-bearing properties are world-relative. This is also as desired: the model tracks counterfactual name-bearing in terms of which assignments are licensed at which worlds, and so individuals bear names only contingently, and name nouns shift reference beneath modal operators. Thus if we want to give an interpretation of The Smith might cheat, (12b) in Section 2.1, we can do so as follows.

$$
\begin{aligned}
& \text { a. } \llbracket \text { might } \rrbracket^{g, w}=\lambda \phi_{\langle s, t\rangle} \cdot \exists w^{\prime}\left[w R w^{\prime} \wedge \phi\left(w^{\prime}\right)\right] \\
& \text { b. } \llbracket \text { the } \rrbracket^{g, w}=\lambda P_{\langle e, t\rangle} \cdot \iota x[P(x)] \\
& \text { c. } \llbracket \text { Smith } \rrbracket^{g, w}=\lambda x_{e} . \forall g^{\prime} \in \mathscr{G}(w), i \in \mathscr{V}_{\text {Smith }}\left[g^{\prime}[i \rightarrow x] \in \mathscr{G}(w)\right] \\
& =\lambda x_{e} \cdot x \text { bears Smith at } w \\
& \text { d. } \quad \llbracket \text { cheat } \rrbracket^{g, w}=\lambda x_{e} \text {. } \text { cheat }^{\prime}(w)(x) \\
& \exists w^{\prime}\left[w R w^{\prime} \wedge \operatorname{cheat}^{\prime}\left(w^{\prime}\right)\left(\iota x\left[x \text { bears Smith at } w^{\prime}\right]\right)\right]
\end{aligned}
$$

So The Smith might cheat has a de dicto reading according to which, at some accessible world, the individual within a restricted domain named Smith at that world cheats at that world - possibly different Smiths in different worlds. And likewise for any number of modal environments allowing de dicto scoping.

Hence names qua nouns are themselves not rigid designators in the sense of Kripke 1980, although we'll see that ordinary referential names, which are proprial DPs in argument position, are indeed rigid due to the rigidifying function of the proprial article. 
Patrick Muñoz

\subsection{The proprial article}

We now offer a semantics for the proprial article. The English version is given here, which is phonologically null, as noted in Section 2.2, though it occurs with many overt forms cross-linguistically. The proprial article's semantic function is, similarly to the definite article, to compose with a propertydenoting expression and return an individual. Unlike the definite article, however, its extension is insensitive to the world parameter, and hence on composing with a name, the resulting proprial DP is world-rigid.

The lexical entry for the proprial article is as follows. It hosts a referential index $i$, and on composing with the intension of a property, it returns whichever individual $g(i)$ the assignment of evaluation $g$ maps that index to. ${ }^{16}$

$$
\begin{aligned}
\llbracket \varnothing_{i} \rrbracket^{g, w}=\lambda & P_{\langle\langle v, e\rangle,\langle\langle s,\langle e, t\rangle\rangle}: \\
& \forall g^{\prime}, w^{\prime}, x\left[P\left(g^{\prime}\right)\left(w^{\prime}\right)(x) \leftrightarrow \exists g^{\prime \prime} \in \mathscr{G}\left(w^{\prime}\right)\left[g^{\prime \prime}(i)=x\right]\right] . \\
& g(i)
\end{aligned}
$$

The special semantic function of the proprial article comes from the domain restriction on the property it composes with - this is the material between the colon and period, on the second line of the entry. This domain restriction says that the article denotes a partial function, defined only on properties that an individual has at a world just in case the index on the article is conventionally allowed to map to that individual on some assignment licensed at that world. In other words, the article composes only with name-bearing properties, and in particular with that name-bearing property associated with the index $i$ that it hosts. The effect of this is that where $i \in \mathscr{V}_{n}$, the denotation of the proprial article hosting $i$ composes only with that property denoted by $n$.

For instance, suppose that $1 \in \mathscr{V}_{\text {John }}$, that is that 1 is a John-index. Then $\varnothing_{1}$ composes successfully with John, since the property denoted by John is such that an individual has it at a world just in case some assignment licensed at that world maps 1 to that individual. In other words, for an indi-

16 As a reviewer points out, this entails that indices (non-zero natural numbers) are part of both the object language and the model. If this is bothersome, it can be trivially rectified by taking the indices in the language and model not to be identical, but to stand in a one-toone relation with each other: for example, let indices in the language be negative integers, and those in the model positive, and let an expression indexed with $-i$ be interpreted as whatever the assignment maps $i$ to. 
The proprial article and the semantics of names

vidual to be a John just is for 1 to conventionally map to that individual on some assignment - this follows from the definition of well-behavedness in Section 3.1, which says that for any name-associated index, if that index maps to an individual on some licensed assignment at a world, then that individual bears that name at that world. Thus where $i \in \mathscr{V}_{J o h n}$, the denotation of $\varnothing_{i}$ composes only with the property of bearing the name John, and likewise for any other name. ${ }^{17}$

Where this condition is met, the composition is simple. We have for the proprial name $\varnothing_{1}$ John, occurring in argument position and simply pronounced John, the following, by intensional function application.

$$
\begin{aligned}
\llbracket \varnothing_{1} \mathrm{John} \rrbracket^{g, w} & =\llbracket \varnothing_{1} \rrbracket^{g, w}((\mathrm{John})) \\
& =g(1)
\end{aligned}
$$

That is, so long as the domain restriction is met, the bare referential name John simply denotes whatever the assignment maps the referential index to. Note that the proprial article can't compose with the denotation of the wrong name: if $2 \in \mathscr{V}_{\text {Mary }}$, then $\varnothing_{2}$ must compose with the property of being named Mary, and not the property of being named John, and so $\llbracket \varnothing_{2} \mathrm{John} \rrbracket^{g, w}$ is undefined. The proprial article must further always host a name-associated index: where $i \in \mathscr{V}_{n}$ for no $n$, the domain restriction trivially fails to be met for any name that the article attempts to compose with.

This approach to the proprial article has a number of beneficial consequences. First, it explains the distribution of the article, that is that it composes with names to the exclusion of other nouns. Non-name nouns do not denote name-bearing properties at all, and so the proprial article can never compose with them: thus for example, bare singulars like $\varnothing_{1}$ woman do not occur in English (though see Section 4.3 below for some exceptions).

Second, it explains the fact that names with overt proprial articles, as well as bare names in bare-name languages, resist restrictive modification: this was already seen in (16) with respect to restrictive relative clauses, but seems to hold generally: thus, the John under the table is good, while *John under the table is not. But the denotation in (26) makes sense of this: the properties denoted by restrictively modified names are not equivalent to the property of bearing a name simpliciter, but impose an additional restriction. Thus, John that I know denotes not the property of being named John, but

17 Thus for any $i, i^{\prime} \in \mathscr{V}_{n}, \varnothing_{i}$ and $\varnothing_{i^{\prime}}$ compose only with the very same property, namely that of bearing $n$. In other words, the index itself doesn't change what property is composed with, so long as the indices are associated with the same name. 
the property of both being named John and being known by the speaker, and the proprial article refuses to compose with such a property, since the right-to-left condition of the biconditional isn't met (one can be named John without falling beneath the extension of John that I know). ${ }^{18}$

Third, it explains the fact that proprial names are rigid designators: the denotation in (27) is world-insensitive, and so does not shift beneath modal operators. Thus, Smith might cheat can be composed as follows, where 3 $\in \mathscr{V}_{\text {Smith }}$.

$$
\begin{aligned}
& \text { a. } \llbracket\left[\varnothing_{3} \text { Smith }\right] \text { cheat } \rrbracket^{g, w}=\operatorname{cheat}^{\prime}(w)(g(3)) \\
& \text { b. } \llbracket \text { might }\left[\left[\varnothing_{3} \text { Smith }\right] \text { cheat }\right] \rrbracket^{g, w}=\exists w^{\prime}\left[w R w^{\prime} \wedge \operatorname{cheat}^{\prime}\left(w^{\prime}\right)(g(3))\right]
\end{aligned}
$$

The sentence thus does not have a de dicto reading on which the cheating individual named Smith might vary from world to world. ${ }^{19}$ It is true just in case there is some accessible world at which $g(3)$ cheats. The denotation of the proprial DP is however sensitive to the variable assignment, and thus referential names are variable expressions, as on the classical treatment of pronouns.

Treating names as variables nothing new: cf. Fiengo \& May 1994: pp. 6768, Heim 1998: p. 239, Cumming 2008, Schoubye 2017, and Lasersohn 2017: p. 50. As Cumming in particular emphasizes, this is likely empirically desirable, since names' extensions do shift, just not typically beneath world

18 Non-restrictive modification with proprial names is fine, as in young John, read nonrestrictively, as well as in John, who is young. A treatment of non-restrictive modification is beyond the scope of this paper, but I take this to be exactly what the present proposal predicts, since non-restrictive modification does not restrict the denotation of the noun, but rather adds restrictions on the referent at some other not-at-issue level of meaning unaffected by composition with the article. There appears to be an exception with respect to the ban on restrictive modification with proprial names, involving prenominal adjectives: against Sloat (1969: p. 28), I do think that young John can be read restrictively as well as non-restrictively: thus, Ask young John, not old John. I am skeptical about the importance of this for the present proposal, since names generally can take abnormal restrictive modifiers in prenominal position, including with nouns, for example Ask (the) linguist John, not (the) philosopher John. These odd modifiers that names specifically can take are so far as I know ill-understood.

19 It was noted in Section 2.1 above that bare names also differ from name descriptions in not allowing bound readings of domain restrictions (as easily). This also can be accounted for if, following Schwarz (2012), we take domain restrictions to be introduced via the determiner, and posit that the proprial article, unlike the definite article, introduces no such domain restriction. This may not even need to be posited as such: since proprial DPs simply rigidly refer, it's questionable in what sense they could make use of domain restrictions to begin with. 
The proprial article and the semantics of names

operators, and what I call proprial names occur with covarying readings, for example as donkey anaphora (cf. Geurts 1997: pp. 321-322; Elbourne 2005: p. 182); they can also occur as anaphoric to indefinite antecedents (cf. Maier 2015: p. 323). The empirical validity of the treatment of names as variables is beyond the scope of this paper, but I believe that the present machinery can account for both the existence and marginality of donkey names in interesting ways, and the same goes potentially for other (very rare, very marginal) bound-variable uses of names, which seem to require name-bearing restrictors for their occurrence, as with and ?Every man named John loves John.

Dynamic approaches to proper names (e.g., Maier 2015; Kamp 2015) have also sought to treat names as variable-like, to minimize the difference between them and other definites traditionally treated as variables in static semantics, and to have them trigger presuppositions on name-bearing properties in their identification of referents. Something similar happens on the present approach, as will be seen in Section 4.3 , where such a name-bearing presupposition arises in searching out a referent for the name, and exhibits behavior corresponding to the sort operative in Maier's hyperglobal accommodation. ${ }^{20}$ The following will demonstrate the use of variable assignments in modeling this behavior.

\subsection{Acts of reference using proprial names}

This section clarifies how the semantics for proprial DPs given above relates to acts of reference using those DPs in argument position, and demonstrates that such a use of a name presupposes that its referent bears that name at its world of use.

Any semantics making use of assignments as intensional parameters must provide a bridge principle clarifying how speakers assert propositions, which are classically not assignment-sensitive, using expressions with assignment-sensitive extensions. This principle should minimally offer a schema specifying which proposition a speaker expresses via a speech act of assertion in a context of utterance, when unbound variable expressions are included in the expression being used for the assertion.

20 I don't mean this comparison to (hyper)global accommodation to rule out other ways in which such name-related presuppositions might be accommodated, but a full comparison of the present approach with these dynamic accounts would require an explicit theory of discourse referents and accommodation in embedded contexts. 
For instance, on a classic treatment of pronouns as variable expressions, as in (29) (abstracting away from features of gender, number, and person), such a principle ought to specify to whom an unbound use of a pronoun refers, when that pronoun gets its value solely from the context of utterance. A sentence like (30a) has (30b) as its extension, but this doesn't yet tell us what its semantic content is at a context of utterance.

(29) $\llbracket$ she $_{i} \rrbracket^{g, w}=g(i)$

(30) a. She $_{4}$ left.

b. $\llbracket$ she $_{4}$ left $\rrbracket^{g, w}=\operatorname{leave}^{\prime}(w)(g(4))$

For simplicity, we can assume that in such an utterance of She left, she refers to whomever the speaker intends it to refer to in the context of utterance. ${ }^{21}$ We can then specify which proposition the speaker expresses by uttering (30a) during an assertion in $c$ as follows, where $[\alpha]^{c}$ is the semantic content of $\alpha$ as uttered in $c$, where for any $\alpha$ of extensional type $t,[\alpha]^{c}$ is a proposition, that is an object of type $\langle s, t\rangle$, and where ' $\phi$ ' is a variable over these propositions.

(31) $[\alpha]^{c}=\iota \phi[\forall g$ such that $g$ is consistent with the referential intentions of the speaker in $\left.c\left[\phi=\lambda w_{s} . \llbracket \alpha \rrbracket^{g, w}\right]\right]$.

We thus determine the asserted proposition by quantifying over assignments: the proposition in question is that unique proposition, if there is one, that maps any world $w$ to the extension of $\alpha$ at $w$ and at any assignment $g$ consistent with the speaker's referential intentions. We define consistency with the speaker's referential intentions as follows.

(32) $g$ is consistent with the referential intentions of the speaker in $c$ iff: if the speaker in $c$ intends to refer to $x$ in $c$ using an expression hosting $i$, then $g(i)=x$.

Where the speaker of (30a) intends in $c$ to refer to Mary using she, which hosts 4 (and the speaker intends to refer to no one else), it follows that all and only those assignments $g$ such that $g(4)$ is Mary are consistent with the speaker's referential intentions in $c$. The unique proposition expressed in $c$ is thus as follows.

21 Treating reference as controlled by the speaker's intentions in this way glosses over a number of difficult, but orthogonal, issues. 
The proprial article and the semantics of names

$$
\begin{array}{r}
{\left[\text { she }_{4} \text { left }^{c}=\iota \phi\left[\forall g \text { such that } g(4)=m\left[\phi=\lambda w_{s} . \text { leave }^{\prime}(w)(g(4))\right]\right]\right.} \\
=\lambda w_{s} . \text { leave }^{\prime}(w)(m)
\end{array}
$$

Thus, if the speaker intends to refer to Mary using she in $c$, he expresses the proposition that Mary left in $c$ using this sentence. Likewise, if he intends to refer to Aisha in $c^{\prime}$, he expresses the proposition that Aisha left in $c^{\prime}$ using that same sentence. If however the speaker intends to refer to no individual using she, or intends to refer to multiple, then there is no proposition expressed at all, since in each of these cases, the uniqueness condition on $\phi$ in (31) fails. ${ }^{22}$

Since proprial DPs are also variable expressions, given the results in Section 3.3, this machinery should extend to the referential use of names. With names, however, there is one additional constraint on propositions expressed. Reference is not restricted only by the speaker's intentions, but also by which individuals bear which names: a proprial use of John, for example, presupposes that its referent is named John at the world of use.

This follows from all the above machinery, if one slight modification is made to (31): we quantify not over all assignments $g$, but only those assignments $g \in \mathscr{G}\left(w_{c}\right)$, where $w_{c}$ is the world of $c$, that is the world at which the assertion is made. In other words, we quantify over only those assignments that are licensed at the world of the context. Here the pragmatic value of assignments in force is demonstrated.

(34) $[\alpha]^{c}=\iota \phi\left[\forall g \in \mathscr{G}\left(w_{c}\right)\right.$ such that $g$ is consistent with the referential intentions of the speaker in $\left.c\left[\phi=\lambda w_{s} . \llbracket \alpha \rrbracket^{g, w}\right]\right]$.

22 Proof: Let the speaker of (30a) in $c$ intend to refer to both $x$ and $y$ in $c$ using she, where $x \neq y$. Then there are no assignments consistent with the speaker's referential intentions in $c$, since for any such assignment $g$, by (32) it must be that $g(4)=x$ and $g(4)=y$, which is impossible. So the universal in (31) is vacuously satisfied, and all propositions $\phi$ satisfy the $\iota$-term, meaning there is no such unique proposition. Let there be instead no $x$ such that the speaker in $c$ intends to refer to $x$ in $c$ using she. Then by (32), for any $g$, the value of $g(4)$ is irrelevant to whether $g$ is consistent with the speaker's referential intentions in $c$. So there are assignments $g^{\prime}, g^{\prime \prime}$ consistent with the speaker's referential intentions in $c$, such that $g^{\prime}(4)=x$ and $g^{\prime \prime}(4)=y$, where $x \neq y$. Thus there is no proposition such that for all such assignments $g, \phi=\lambda w_{s}$.leave' $(w)(g(4))$, since both $\lambda w_{s}$.leave ${ }^{\prime}(w)(x)$ and $\lambda w_{s}$.leave' $(w)(y)$ satisfy the constraint on some such consistent assignment. Thus no $\phi$ satisfies the $\iota$-term. 
Suppose that the speaker utters (35a), whose extension is given in (35b), in $c$. Recall from Section 3.3 that it must be that $1 \in \mathscr{V}_{\text {John }}$, or else presupposition failure results.

(35) a. $\varnothing_{1}$ John left.

b. $\llbracket\left[\varnothing_{1}\right.$ John $]$ left $\rrbracket^{g, w}=$ leave' $(w)(g(1))$

Plugging into (34), we have the following.

(36) $\left[\left[\varnothing_{1} \mathrm{John}\right] \text { left }\right]^{c}=\iota \phi\left[\forall g \in \mathscr{G}\left(w_{c}\right)\right.$ such that $g$ is consistent with the referential intentions of the speaker in $c\left[\phi=\lambda w_{s}\right.$.leave $\left.\left.(w)(g(1))\right]\right]$

Suppose further that the speaker intends to refer only to John Smith in $c$ using $\varnothing_{1}$ John. In order to express the proposition that John Smith left, that is $\lambda w_{s}$.leave $(w)(s)$, which is the only proposition that is consistent with the speaker's referential intentions, there must be some assignment $g \in$ $\mathscr{G}\left(w_{c}\right)$ such that $g(1)$ is John Smith. If there weren't, then there would be no assignments licensed in $w_{c}$ to quantify over consistent with John's referential intentions, and hence there would be no unique proposition expressed.

But because of the well-behavedness condition in Section 3.1, whenever there are some $g \in \mathscr{G}(w)$ and $i \in \mathscr{V}_{n}$ such that $g(i)=x$, then $x$ bears $n$ at $w$. Thus, so long as there is some assignment licensed at the world of utterance, which maps the John-index 1 to John Smith, then it follows that John Smith bears John at $w_{c}$. But since this is what is required, given the speaker's referential intentions, in order to express a proposition using this sentence in $c$, it follows that the sentence expresses a proposition only if the intended referent, John Smith, is named John at the world of the context.

To make this clearer, take a case where reference fails due to calling an individual the wrong name. Suppose that the speaker in $c^{\prime}$ utters (35a), and intends to refer to Mark Hamill using $\varnothing_{1}$ John in $c^{\prime}$, and further suppose that Mark Hamill is not named John at $w_{c^{\prime}}$. Then there are no $g \in \mathscr{G}\left(w_{c^{\prime}}\right)$ and $i \in \mathscr{V}_{\text {John }}$ such that $g(i)$ is Mark Hamill. But since all assignments $g$ consistent with the speaker's referential intentions in $c^{\prime}$ are such that $g(1)$ is Mark Hamill, it follows that there are no assignments licensed at $w_{\mathcal{c}^{\prime}}$ consistent with her intentions in $c^{\prime}$. Thus nothing satisfies the restrictor for the universal quantifier in (36), meaning that the universal statement is vacuously satisfied by any $\phi$. It follows that there is no unique $\phi$ that meets the condition, and so no proposition is expressed. 
The proprial article and the semantics of names

Thus where an unbound proprial name is intended to refer to an individual, a proposition is expressed only if that individual bears that name at the context in which the proprial DP is used. Othwerise, presupposition failure results. ${ }^{23}$

It's important to note that the appeal to assignments in force at the world of utterance to determine which proposition is expressed by a use of a proprial name in no way impacts the rigidity of these proprial names. The extension of a proprial DP remains insensitive to the world parameter, and the world of evaluation plays no role in determining their contribution to the proposition expressed at a context of utterance. Rather, the name-bearing properties holding at the world of utterance determine in part whether a proposition is expressed at all.

To see this, take again the sentence Smith might cheat, where again 3 $\in \mathscr{V}_{\text {Smith }}((37 \mathrm{a})$ is repeated from (28b)). The proposition expressed by this sentence in a context $c$ is then as in (37b).

$$
\begin{aligned}
& \text { a. } \left.\llbracket \text { might }\left[\left[\varnothing_{3} \text { Smith }\right] \text { cheat }\right]\right]^{g, w}=\exists w^{\prime}\left[w R w^{\prime} \wedge \text { cheat }^{\prime}(w)(g(3))\right] \\
& \text { b. }\left[\text { might }\left[\left[\varnothing_{3} \text { Smith }\right] \text { cheat }\right]\right]^{c}=\iota \phi\left[\forall g \in \mathscr{G}\left(w_{c}\right)\right. \text { such that }
\end{aligned}
$$

$g$ is consistent with the referential intentions of the speaker in $c\left[\phi=\lambda w_{s} \cdot \exists w^{\prime}\left[w R w^{\prime} \wedge\right.\right.$ cheat $\left.\left.\left.^{\prime}\left(w^{\prime}\right)(g(3))\right]\right]\right]$

Supposing that the speaker in $c$ intends only to refer to John Smith in $c$ using $\varnothing_{3}$ Smith, and that John Smith is named Smith in $w_{c}$, then the result is as follows. If however the speaker does not intend to refer to any unique individual in $c$, or intends to refer to a unique individual not named Smith in $w_{c}$, then no proposition is expressed, for the reasons stated above.

$$
\begin{aligned}
& \text { [might } \left.\left[\left[\varnothing_{3} \text { Smith }\right] \text { cheat }\right]\right]^{c}=\iota \phi\left[\forall g \in \mathscr{G}\left(w_{c}\right)\right. \\
& \text { such that } \left.g(3)=s\left[\phi=\lambda w_{s} \cdot \exists w^{\prime}\left[w R w^{\prime} \wedge \operatorname{cheat}^{\prime}\left(w^{\prime}\right)(g(3))\right]\right]\right] \\
& =\lambda w_{s} \cdot \exists w^{\prime}\left[w R w^{\prime} \wedge \operatorname{cheat}^{\prime}\left(w^{\prime}\right)(s)\right]
\end{aligned}
$$

Thus the proposition expressed is that at some world accessible from the world of evaluation, $s$ cheats. It is irrelevant to the determined proposition what names $s$ bears in what worlds, and $s$ cannot vary across worlds; the

23 I take it that in cases of wrong name-calling, charitable interlocutors able to recover the intentions of the speaker can repair the speaker's presupposition failure, and construe them as having said what they attempted, but in some sense failed, to say. This does not diminish the fact that presupposition failure has occurred, and that speakers competent with namebearing properties are aware of this: it only means that speakers can often correct for the mistakes of their interlocutors, as is the case for wrong uses of words generally. 
proposition is a de re one concerning that individual. Hence despite the relative complexity of the machinery this account employs, the resulting semantic contribution of unbound proprial names is extremely simple: they contribute an individual to the proposition that they take part in expressing, and nothing more. But this is so only if that individual is the unique one (i) intended to be referred to by the speaker and (ii) actually bearing the name in question at the world of utterance. ${ }^{24}$

\section{Comments}

This section presents some further comments on the proposal offered in Section 3. Section 4.1 clarifies how the current approach compares with socalled referentialist accounts of names in the literature; Section 4.2 offers some notes on its consequences for the notion of name-bearing; and Section 4.3 shows how the present treatment of the proprial article can extend to other linguistic phenomena.

\subsection{Conciliation with referentialism}

The foregoing has adopted the position, sometimes called predicativist in the literature, that names occur in the lexicon as property-denoting count nouns, and that ordinary referential names in argument position occur, in languages with the relevant article systems, as the result of these composing with an article. There is in the literature a view that sometimes goes under the moniker of referentialism, according to which names are rigidly referring referential expressions, and this view is often taken to contrast with the sort of approach presented here: there are works (cf. Jeshion 2015;

24 A reviewer asks how the present approach differs from that of Burge 1973, which holds that names are name-bearing predicates, and that as referential expressions in argument position they act as singular terms denoting a contextually-determined object bearing the name in question, such that these names '...play the roles of a demonstrative and a predicate' (ibid. 423). I have no issue with taking the present account to be an elaboration of a broadly Burgean view of names. But there can be no question of whether or how the present account differs from his in any detail, because Burge doesn't intend to offer a theory of names at the level of description at which the present proposal operates: he doesn't discuss any linguistic mechanism by which referential names are to be composed, either as to what linguistic object if any mediates between the name-predicate and the referential name, or as to how the compositional semantics works; and he offers no treatment of name-bearing. There is also no commitment on the present approach to proprial names being demonstratives. 
The proprial article and the semantics of names

Rami 2015) dedicated in part to defense of the referentialist position against its purported opponent.

But it is not at all obvious that predicativism so-called and referentialism so-called conflict in any interesting way. The reason for this is that referentialists have largely objected to predicativism on grounds that referential names in argument position do not behave like definite descriptions (cf. Section 2.1), and though this position has long been associated with predicativism, this has been only by accident. The foregoing has dispensed with it, leaving proprial names in argument position as non-descriptive rigid designators, just as the referentialist desires.

A problem with the above-mentioned referentialist criticisms is that they often don't clarify at what level of syntactic description their claims are made, and in general they don't address the function of articles with referential names. When speaking of a name, we may mean any number of things, but especially we may mean a name qua noun in the lexicon (or NP), or name qua referential argument (or DP) that subsumes an article with which the noun occurs as well, whether that article is phonologically null or not. Both need to be explicated to form a coherent account of the semantics of names. Only when some construal of both positions in these terms is made can there be any question of a conflict between them.

Once the claims made by each party - that names are name-bearing predicates in the lexicon, and that names are rigidly-denoting referential expressions - are clarified in a certain way as to their level of syntactic description, there is no reason that they both cannot be literally true, with no special stipulation: qua nouns or NPs, names are name-bearing predicates, and qua proprial DPs, they are rigidly designating referential expressions. And in fact just such an account that verifies both these claims has been provided here. Understood this way, the two views are not in conflict.

Of course, the position taken here rules out some possible implementations of the referentialist thesis. For instance, it is incompatible with the idea that referential names are intransitive Ds (cf. Matushansky 2015: pp. 335-336; Schoubye 2017: p. 739), akin to some classical analyses of pronouns and simplex demonstratives (cf. Abney 1987: pp. 278-284). But this cannot be a fully general hypothesis about the syntactic status of names anyway, as it does not allow for names to occur with overt articles, as they do in a number of languages.

But the referentialist hypothesis is often taken also to include an additional thesis, namely that names are not name-bearing count nouns in the 
lexicon, as suggested in Section 2, but rather occur there as referential expressions, either as nouns or intransitive determiners. Given that the primary concern of the referentialists has been to ensure that referential names are rigidly-denoting referential expressions in argument position, and that per the above this is perfectly compatible with names being name-bearing count nouns in the lexicon, the appeal of this additional thesis is not obvious. As noted in Section 2, it requires that some alternative explanation be proffered for the huge array of environments in which names do have a transparently predicative function.

To this end, many authors have offered mechanisms for deriving predicative names from their more basic referential counterparts, but none so far as I'm aware is without its problems: Gray (2017) offers an inconclusive but pessimistic survey of the referentialist's prospects here.

For instance, Schoubye (2017: pp. 736-740) proposes that predicative names are derived from referential names, at least in English, via morphological zero-derivation. This predicts that the availability of predicative names in a language is dependent on the presence of a morphological mechanism in that language, and that their overt form is dependent on how that mechanism happens to be overtly marked. There is no reason to expect that such a marking ought to be null in all languages in which it occurs. Though the descriptive work on predicative names is still spotty, I'm aware of no language that either lacks such names, or marks them with some overt morphology this is negative evidence against a general morphological mechanism, insofar as predicative names ought to be missing where the mechanism is unavailable in a particular language, and overtly marked where the derivational morphology happens not to be phonologically null. ${ }^{25}$

Other authors prefer narrowly semantic or pragmatic mechanisms for deriving predicative from referential names. Leckie (2013), Rami 2015, and

25 A reviewer notes that it is no mark against a proposed zero-derivation that there is no overt morphological marking of such a derivation, since by definition a zero-derivation has no such marking. The point is not that we ought to expect overt marking in those languages for which a zero-derivation is proposed, nor even that we ought to find it in some prespecified proportion of languages. The point is rather that if the general mechanism by which predicative names are derived from referential names is indeed morphological, then this opens up the possibility that the purported morphology is overtly marked, rather than the result of a zero-derivation, in some language in which it occurs. To deny this is to make a very unpalatable claim, namely that to the extent that all languages have predicative names, and to the extent that they are never overtly marked, then there is a morphological marker with just this function in every language, and in every language it is phonologically null. 
The proprial article and the semantics of names

Jeshion (2015: pp. 379-385) offer proposals in this vein, where a predicative name is the result of some derivation from a referential counterpart (either the word itself, or the form or generic name associated with it), via systematic polysemic or metalinguistic means, or by Nunberg's (1995) pragmatically triggered transfers of meaning, such that roughly an individual falls beneath the name-predicate's extension just in case it's an appropriate referent of an associated referential name. The main deficiency of these accounts is that they don't explain why the relevant semantic or pragmatic mechanisms for such derivations are so much more productive with names than with other referential expressions: for instance, predicative pronouns (as in, Mary is a she) don't occur naturally in the range of contexts that predicative names do, as in (4). ${ }^{26}$

And so there is an empirical issue at stake in the referentialist literature, insofar as it claims that referential names in argument position are somehow primary (perhaps in that names are type-e in the lexicon), and that predicative names are derived from them by some means. It's worth noting that the present machinery has no problem being modified to accommodate such a view. Keeping the name-bearing machinery from Section 3.1 and the pragmatic machinery from Section 3.4, it is perfectly possible to cast a name qua noun as a referential expression in the lexicon, rather than a predicate, as follows.

$$
\begin{array}{ll}
\text { a. } & \llbracket n_{i} \rrbracket^{g, w}=g(i), \\
& \text { if } i \in \mathscr{V}_{n}^{2} ; \text { else undefined } \\
\text { b. } & \llbracket \mathrm{John}_{i} \rrbracket^{g, w}=g(i), \\
& \text { if } i \in \mathscr{V}_{\text {John }} ; \text { else undefined }
\end{array}
$$

There is then no trouble with defining an operator that converts referential names into their predicative counterparts, as follows, where again $1 \in$ $\mathscr{V}_{\text {John }}{ }^{27}$

26 I don't know the cross-linguistic facts regarding the distribution of predicative use of pronouns: Schoubye (2017: p. 736, fn. 31) suggests that there is variation even among the Germanic languages, with English perhaps being on the restrictive side in their distribution. This variation is not what one would expect if the process deriving both predicative names and pronouns involves cross-linguistically robust lexical rules (as Rami ibid. entertains); nor does it help explaining why intra-linguistically, the same process sometimes yields different results for names versus pronouns.

27 Of course, an approach like this would still need to figure out what to do with the proprial article. It could be cast as semantically vacuous, for example by having it denote the identity function on individuals; presumably the restrictions on combining with non-name nouns, 
(40) $\quad$ a. $\quad \llbracket \mathrm{Op}_{\text {pred }} \rrbracket^{g, w}=\lambda x_{\langle\langle v, e\rangle,\langle s, e\rangle\rangle} \cdot \lambda y_{e} \cdot \exists g^{\prime} \in \mathscr{G}(w)\left[x\left(g^{\prime}\right)(w)=y\right]$

b. $\llbracket \mathrm{John}_{1} \rrbracket^{g, w}=g(1)$

c. $\quad \llbracket \mathrm{Op}_{\text {pred }} \mathrm{John}_{1} \rrbracket^{g, w}=\lambda y_{e} . \exists g^{\prime} \in \mathscr{G}(w)\left[g^{\prime}(1)=y\right]$

$=\lambda y_{e} \cdot y$ bears John at $w$

Whether one of these sorts of names is derived from the other is thus an empirical rather than a conceptual question, and ought to be decided based on whether there is any evidence that there exist linguistic operators that perform such a conversion from one to the other. I'm aware of no evidence for an operator like (40a) - if some turns up, it can be accommodated as above. But there is evidence for an operator that does the reverse, converting predicative names, as nouns, into rigidly denoting arguments. That operator manifests in some languages as the proprial article, hence the view taken here.

\subsection{On name-bearing properties}

In Section 3 it was promised that the account given here would provide an intuitively plausible notion of name-bearing. It does this by casting namebearing as inherently linked to reference using proper names. Bearing a name is characterized in terms of licensed assignments and name-associated indices, but these indices are themselves just ways of modeling reference secured in the use of proprial DPs. The result, seen in Section 3.4, is that for an individual to bear a name at a world just is for that individual to be a possible referent of that name as used at that world - and by that very fact, said individual also falls beneath the name qua predicate, at that world as world of evaluation. In other words, for any world at which an individual is an $n$, ' $n$ ' can be used at that world in a proprial DP to refer to that individual.

It's a further question exactly how the world must be in order for licensed assignments to be structured as in the definition in (20), so that in a linguistic community, an individual is an appropriate referent of a name-associated index. We might ask, first, what practices actually result in individuals coming to bear names. I doubt there is any comprehensive answer to this ques-

and the ban on restrictive modification, would then be type-theoretically driven, given that the article composes with expressions of type $e$, leaving nouns as a class primitively heterogenous as to their semantic type. This explanation for the behavior of the article seems as serviceable to me as the one I offer above; the issue is then simply there is no empirical reason to believe that predicative names are derived from referential ones, rather than vice-versa. 
The proprial article and the semantics of names

tion. The prevailing sociolinguistic and onomastic conventions as to how the speech community comes to treat certain referential mappings as appropriate can be documented, but it matters little whether the arrangement happens due to a meteor strike addling everyone's brains: so long as one ends up an appropriate referent of a name, one bears it. As Geurts (1997: p. 328) says: 'the expression "bearing a name" covers as many relations as there are naming practices.' I'll add: '... and more.' Read one way, this claim is false - the one way to bear a name is to be a conventional referent of it. Read another way, it's true, in that there's no one way by which things become such conventional referents.

We might ask, second, what exactly the result state is of any such practice, such that the use of licensed assignments appropriately models it. The above has suggested that to bear a name is to be an appropriate referent of that name at its world of use, where appropriateness has been modeled, per Section 3.4, as the use of the name not resulting in presupposition failure. And so the circle is complete: uses of the name to refer either cause presupposition failure, or they don't - this is determined, for example, by whether speakers do or don't habitually and ingenuously offer corrections, or exhibit confusion or resistance, when the name is used. For there to be no such failure-reactions just is for a name-bearing relation to hold. ${ }^{28}$

Whether presupposition failure results from the use of a name is a normative notion, that cannot simply track the actual referential behavior of speakers in a community, or their reaction to that behavior. For instance, as Gray (2014: p. 213) notes, an individual need not actually be referred to by a name to bear it. The present approach allows for this, since the licensed assignments can be so disposed to allow such conventional reference, without these dispositions ever being actualized, either because the use of a name is taboo, or by happenstance. Thus even if a name isn't used, it would or would not tend to cause presupposition failure if used.

There is in turn a deeper way in which name-bearing is normative: since there is no property to which name-bearing corresponds other than whether or not use of a name to refer would result in presupposition failure, speakers can take a stand on which name-bearing relations hold by purposefully

28 And so one way to become an appropriate referent is simply to be an actual referent for long enough that everyone is habituated to using the name without objection, and so-called reference transfer occurs. Even a single use of a name to refer can serve to accommodate the presupposition that said name is now properly so-used: all it takes is no one ever complaining about it, and so no presupposition failure ever resulting. 
engaging in or refusing to engage in behavior constitutive of presupposition failure at the use of a name. This can result in fine-grained idiolectal differences, where there is disagreement as to who is an appropriate referent of what name, because certain individuals do not accept certain naming conventions as authoritative: this would happen, for example, when someone's opponent devises a cruel nickname for them, so that it enters wide circulation, yet the nicknamee insists that it is not their name. In the unfortunate soul's idiolect (as in that of anyone agreeing with them), the licensed assignments are different, since using the name with them does in fact cause presupposition failure.

\subsection{Some extensions}

The above has dealt with ordinary proper names, but the proprial article occurs in some other environments as well - it's worth considering how the present approach might shed light on these constructions.

First, as noted in Section 2.2, the proprial article occurs with certain count nouns not typically thought of as names, such as mom, to form so-caled quasi-names. In English, where the proprial article is null, this means that the bare singular Mom occurs in argument position, as in (41) (as noted previously, such nouns can also occur with overt proprial articles, at least in Icelandic).

(41) Mom went to the airport.

According to Section 3.3, the proprial article's denotation composes only with name-bearing properties: assuming that the noun mom is identical in its use as ordinary count noun and quasi-name, this means that the property denoted by mom is a name-bearing property as well as the property of being a mother. There is no technical impediment to implementing this: we only say that nouns that act as quasi-names have referential indices associated with them as well, but that unlike the indices of true proper names, whether they are conventionally allowed to map to an individual on licensed assignments tracks whether the individual has some non-linguistic property, such as being a mother.

So let there be, for each noun $q$ that can be used as a quasi-name, a denumerably infinite set of referential indicies $\mathscr{V}_{q}$, just as for proper names. Name-bearing is then constrained by the corresponding property denoted 
The proprial article and the semantics of names

by the count noun, as in (42a), which by the definition of name-bearing in Section 3.1 converts to (42b).

(42) a. For all quasi-names $q$, individuals $x$, and worlds $w$ :

For all $g \in \mathscr{G}(w), i \in \mathscr{V}_{q}: g[i \rightarrow x] \in \mathscr{G}(w)$ iff:

for some $g^{\prime}:(q)\left(g^{\prime}\right)(w)(x)$

b. $\quad x$ bears $q$ in $w$ iff:

for some $g:(q)(g)(w)(x)$

Then given an ordinary denotation for the quasi-name mom (43), this schema is instantiated as follows.

(43) $\llbracket \mathrm{mom} \rrbracket^{g, w}=\lambda x_{e} \cdot$ mother $^{\prime}(w)(x)$

(44) a. For all $g \in \mathscr{G}(w), i \in \mathscr{V}_{\text {mom }}: g[i \rightarrow x] \in \mathscr{G}(w)$ iff: mother' $^{\prime}(w)(x)$

b. $x$ bears mom in $w$ iff: $\operatorname{mother}^{\prime}(w)(x)$

That is, an individual bears the quasi-name mom at a world just in case that individual is a mother at that world, and likewise for any quasi-name. Whether a count noun is also a quasi-name just depends on whether there is such an associated set of referential indices in the language, and this will be subject to various cross-linguistic regularities. Then assuming that $5 \in \mathscr{V}_{\text {mom: }}$

(45) $\llbracket \varnothing_{5} \mathrm{mom} \rrbracket^{g, w}=g(5)$

Where according to the mechanisms in Section 3.4, any referent of $\varnothing_{5} \mathrm{mom}$ must be a mother at the world of utterance. ${ }^{29}$

29 Mom also preferentially denotes the speaker's mother, though this seems to be just a pragmatic default. Interestingly, because of the denotation of the proprial article given in Section 3.3, this approach predicts that once certain restricted referential indices exist in the language, whether a noun can be used as a quasi-name depends on its denotation rather than its overt form: thus any noun that means the same as mom ought to be able to be used as a quasi-name too. It would be interesting to see if this holds generally, but the preliminary evidence for this semantically-driven view is heartening: mother can be used as a quasi-name too, and the same goes for example for dad, father, papa, etc. Note also that this approach predicts rightly that mother of Mary cannot be used as a quasi-name: this follows, since such a noun denotes not the property of being a mother simpliciter, but of being a mother of Mary, which the proprial article's denotation will refuse to compose with. 
Patrick Muñoz

Second, the proprial article occurs with other sorts of expressions in some languages. For instance, in Māori, it can sometimes occur with personal pronouns and certain locational nouns.

$$
\begin{aligned}
& \text { a. ... kua titiro mai te iwi rā ki a ia } \\
& \text { TAM look hither the tribe dist to PROP 3.SG } \\
& \text { '...the tribe had been looking at her.' [Māori. Bauer 2003: p. 143] } \\
& \text { b. ... e kore e tiro-hia a raro. } \\
& \text { TAM neg TAM look-pass PROP underneath } \\
& \text { '...the bottom would not be searched.' } \\
& \text { [ibid. p. 144] }
\end{aligned}
$$

[ibid. p. 144]

There is no reason in principle the approach for quasi-names ought not to function here as well, though the properties in question that govern for example ia-indices or raro-indices would need to be properly finessed. I don't want to be hasty these constructions: they will undoubtedly provide challenges for future research, but their behavior is largely unknown to me. ${ }^{30}$

Finally, it's worth noting that while the present discussion has been somewhat parochial, being limited to DP languages with article systems, the mechanisms here are generalizable. In non-DP languages, or languages without articles, the function played by the proprial article, and the way it affects name-bearing predicates and reference using names, can still be made use of, as part of their general mechanisms for expressing definiteness using nouns, whatever they are. That this function happens to be realized on an article in the languages under consideration here is, I take it, a cross-linguistic accident.

30 A reviewer worries that the fact that the proprial article occurs with Māori pronouns may be troublesome for the present approach, since of course pronouns do not always occur as strictly referential, but have various covarying, anaphoric, and bound interpretations. So far as I can see, this is not a problem. Since the proprial article forms variable expressions (per Section 3.3), the semantics offered for Māori pronouns will not differ interestingly from the classical treatment of pronouns as variable expressions, and so whatever resources are employed to offer such readings of ordinary pronouns will be available here, and vice-versa. Whether there are ultimately problems with such approaches for some readings of pronouns, their efficacy won't depend on these facts about Māori, but on general facts about pronouns cross-linguistically. I also want to stress that I do not even know whether Māori pronouns with the proprial article occur in the same range of environments as pronouns in other languages: this is something that has to be shown, before anyone starts considering the theoretical implications of the fact in (46a). 
The proprial article and the semantics of names

\section{Conclusion}

The literature surrounding the semantics of names has long been attracted to the idea that names are count nouns that denote the property of bearing that very name. Acceptance of this position has long been hampered by difficulties that this view faces in treating referential names in argument position, and in particular by the hypothesis that such names are definite descriptions. The existence of the proprial article speaks against this hypothesis, and suggests that in DP languages making use of articles, a unique functional element serves to compose with names as nouns to return referential expressions composed of an article and name in argument position. Once this is recognized, a number of puzzles concerning the semantic behavior of proper names disappear, and it becomes possible to substantively characterize name-bearing properties in terms of the referential acts that these proprial DPs are employed for.

While the semantics of names is of intrinsic interest, the further hope of the present work is that the proprial article be taken seriously in this proposed capacity by semanticists, and take its place alongside the definite article in their inventory, as a semantically distinct functional element.

\section{References}

Abney, Steven Paul. 1987. The English noun phrase in its sentential aspect. Cambridge, MA: Massachusetts Institute of Technology dissertation. http: //hdl.handle.net/1721.1/14638.

Bach, Kent. 1981. What's in a name. Australasian Journal of Philosophy 59(4). 371-386. https://doi.org/10.1080/00048408112340341.

Bauer, Winifred. 2003. The Reed reference grammar of Māori. 2nd. Auckland, New Zealand: Reed.

Burge, Tyler. 1973. Reference and proper names. Journal of Philosophy 7o(14). 425-439. https://doi.org/10.2307/2025107.

Campbell, George L. 1991. Compendium of the world's languages, vol. 2: Maasai to Zuni. London \& New York: Routledge.

Coromina i Pou, Eusebi. 2001. L'article personal en català: Marca d'oritalitat en l'escriptura. Universitat Autónoma de Barcelona dissertation. https: //www.tdx.cat/handle/10803/4824.

Cumming, Sam. 2008. Variabilism. Philosophical Review 117(4). 525-554. https: //doi.org/10.1215/00318108-2008-015. 
Delsing, Lars-Olof. 1993. The internal structure of noun phrases in the Scandanavian languages. University of Lund dissertation. https:// portal . research.lu.se/en/publications/o81317dg-f3cb-4d7b-892d-a8288e24724e. Elbourne, Paul. 2005. Situations and individuals. Cambridge, MA: MIT Press.

Fara, Delia Graff. 2015a. A problem for predicativism solved by predicativism. Analysis 75(3). 362-370. https://doi.org/10.1093/analys/anv042.

Fara, Delia Graff. 2015b. Names are predicates. Philosophical Review 124(1). 59-117. https://doi.org/10.1215/00318108-281266o.

Fiengo, Robert \& Robert May. 1994. Indices and identity. Cambridge, MA: MIT Press.

Geurts, Bart. 1997. Good news about the description theory of names. Journal of Semantics 14(4). 319-348. https://doi.org/10.1093/jos/14.4.319.

Gray, Aidan. 2012. Names and name-bearing: An essay on the predicate view of names. University of Chicago dissertation.

Gray, Aidan. 2014. Name-bearing, reference, and circularity. Philosophical Studies 171(2). 207-231. https://doi.org/10.1007/s11098-013-0262-z.

Gray, Aidan. 2017. Names in strange places. Linguistics and Philosophy 40(5). 429-472. https://doi.org/10.1007/s10988-017-9205-Z.

Gray, Aidan. 2018. Lexical-rule predicativism about names. Synthese 195. 55495569. https://doi.org/10.1007/s11229-017-1462-4.

Harlow, Ray. 2001. A Māori reference grammar. Auckland, New Zealand: Pearson Education New Zealand.

Hawthorne, John \& David Manley. 2012. The reference book. Oxford: Oxford University Press. https://doi.org/10.1093/acprof:0so/9780199693672. 001.0001.

Heim, Irene. 1998. Anaphora and semantic interpretation: A reinterpretation of Reinhart's approach. In Uli Sauerland \& Orin Percus (eds.), The interpretive tract (MIT Working Papers in Linguistics 25), 205-246. Cambridge, MA: MITWPL.

Holton, David, Peter Mackeridge, Irene Philippaki-Warburton \& Vassilios Spyropoulos. 2012. Greek: A comprehensive grammar. 2nd edn. London \& New York: Routledge.

Jeshion, Robin. 2015. Referentialism and predicativism about proper names. Erkenntnis 8o(S2). 363-404. https://doi.org/10.1007/s10670-014-9700-3. Kamp, Hans. 2015. Using proper names as intermediaries between labelled entity representations. Erkenntnis 8o(S2). 263-312. https://doi.org/10. 1007/s10670-014-9701-2. 
The proprial article and the semantics of names

Kneale, William. 1962. Modality de dicto and de re. In Ernest Nagel, Pat Suppes \& Alfred Tarski (eds.), Logic, methodology, and philosophy of science: Proceedings of the 1960 International Congress, 622-633. Stanford, CA: Stanford University Press. https: / / doi.org / 10 . 1016 / Soo49-237X(og) 70626-3.

Kripke, Saul. 1980. Naming and necessity. Cambridge, MA: Harvard University Press.

Lasersohn, Peter. 2017. Subjectivity and perspective in truth-theoretic semantics. Oxford: Oxford University Press.

Leckie, Gail. 2013. The double life of names. Philosophical Studies 165(3). 11391160. https://doi.org/10.1007/s11098-012-0008-3.

Loar, Brian. 1976. The semantics of singular terms. Philosophical Studies 30(6). 353-357. https://doi.org/10.1007/BFo0372537.

Longobardi, Guiseppe. 1994. Reference and proper names: A theory of Nmovement in syntax and logical form. Linguistic Inquiry 25(4). 6o9-655. http://www.jstor.org/stable/4178880.

Maier, Emar. 2015. Reference, binding, and presupposition: Three perspectives on the semantics of proper names. Erkenntnis 80(S2). 313-333. https: //doi.org/10.1007/s10670-014-9702-1.

Matushansky, Ora. 2006. Why Rose is the Rose: On the use of definite articles in proper names. Empirical issues in syntax and semantics 6. 285-307. http://www.cssp.cnrs.fr/eiss6/matushansky-eiss6.pdf.

Matushansky, Ora. 2008. On the linguistic complexity of proper names. Linguistics and Philosophy 31(5). 573-627. https://doi.org/10.1007/s10988008-9050-1.

Matushansky, Ora. 2015. The other Francis Bacon: On non-bare proper names. Erkenntnis 80(S2). 335-362. https://doi.org/10.1007/s10670-014-9703-0.

Nunberg, Geoffrey. 1995. Transfers of meaning. Journal of Semantics 12(2). 109-132. https://doi.org/10.1093/jos/12.2.109.

Pelczar, Michael \& Joseph Rainsbury. 1998. The indexical character of names. Synthese 114(2). 293-317. https://doi.org/10.1023/A:1004992629004.

Perini, Mário A. 2002. Modern Portuguese: A reference grammar. New Haven, CT: Yale University Press.

Rami, Dolf. 2015. The multiple uses of proper nouns. Erkenntnis 80(S2). 405432. https://doi.org/10.1007/s10670-014-9704-Z.

Schoubye, Anders J. 2016. A problem for predicativism not solved by predicativism. Semantics and Pragmatics 9(18). 1-11. https://doi.org/10.3765/ sp.9.18. 
Schoubye, Anders J. 2017. Type-ambiguous names. Mind 126(503). 715-767. https://doi.org/10.1093/mind/fzv188.

Schoubye, Anders J. 2018. The predicative predicament. Philosophy and Phenomenological Research 96(3). 571-595. https://doi.org/10.1111/phpr. 12336.

Schwarz, Florian. 2012. Situation pronouns in determiner phrases. Natural Language Semantics 20(4). 431-475. https://doi.org/10.1007/s11050012-9086-1.

Sigurðsson, Halldór Ármann. 2006. The Icelandic noun phrase: Central traits. Arkiv för nordisk filologi 121. 193-236. https://journals.lub.lu.se/anf/ article/view/11754/10433.

Sloat, Clarence. 1969. Proper nouns in English. Language 45(1). 26-30. https: //doi.org/10.2307/411749.

Wood, Jim. 2009. Icelandic impostors and the proprial article. In Patricia Irwin \& Violeta Vázquez Rojas Maldonado (eds.), NYU working papers in linguistics, volume 2, Spring 20og: Papers in syntax. New York University. http://as.nyu.edu/content/dam/nyu-as/linguistics/documents/nyuwpl/ wood_o9_icelandic_imposters_nyuwpl2.pdf.

Patrick Muñoz

Department of Linguistics

University of Chicago

1115 E. 58th St.

Chicago, IL 60637, USA

pjmunoz@uchicago.edu 